\title{
Hubungan Paparan Timbal Dalam Darah dengan Kejadian Hipertensi Pada Pekerja Industri Pengecoran Logam Di Ceper Klaten Tahun 2015
}

\author{
The relationship between Blood Lead Level (BLL) with Hypertention on Gen Metal Casting \\ Industry Workers In Klaten Ceper 2015
}

\author{
Sigit Tri Ambarwanto, Nurjazuli, Mursid Raharjo
}

\begin{abstract}
ABSTRACK
Background: The problem of heavy metal pollution is a serious problem in Indonesia. This metal has been known to be stored in the body for long periods of time as toxins accumulate. Preliminary test results BLL on workers in the metal casting Ceper, found as many as 16 (5.61\%) BLL on workers is under (NAB) and 17 $(5.28 \%)$ workers above (NAB). The research was conducted to determine the relationship between the exposure of lead $(\mathrm{Pb})$ in blood with hypertension in foundry workers CV. Fortification Jaya Batur, Ceper, Klaten. Methods: It was an observational study with Cross Secional design. The population in this study were all workers CV. Jaya fortification. Samples are workers CV. Fortification Jaya who met the inclusion criteria. Gathering data using questionnaires tools, inspection $P B$ in the air using Gravimetry, Pb in the blood examination using AAS (automatic Absorption Spectrophotometer) and hypertension examination tension meter is measured using a needle.

Results: The average air Pb $0.13756 \mathrm{mg} / \mathrm{dl}$, the average BLL was 14.38096 $\mu \mathrm{g} / \mathrm{dl}$. Chi Square test results showed that there was no relationship between the type of work with hypertension $(p=0.625)$, There is a relationship between levels of air $\mathrm{Pb} P \mathrm{~Pb}$ levels in blood $(p=0.019)$, There is a relationship between levelsof lead in blood with hypertension $(p=0.042)$.

Conclusions:Levels of Air Pb Pb levels in the blood affects that can cause hypertension.
\end{abstract}

Keywords: Hypertension, Blood Lead Level, Klaten

\section{PENDAHULUAN}

Pertumbuhan kota dan perkembangan industri yang mengikutinya telah mendorong timbulnya kesadaran dan pengertian adanya hubungan timbal balik antara pencemaran, kesehatan umum dan lingkungan. Pengetahuan mengenai dampak pencemaran terhadap kesehatan masyarakat berkembang terus, baik secara langsung melalui pemakaian suatu bahan tertentu atau secara tidak langsung melalui rantai makanan. ${ }^{1}$ Manusia di dalam kehidupannya memerlukan makanan untuk mempertahanakan hidup.

Manusia sebagai makhluk hidup tertinggi di dunia, hidupnya sangat bergantung pada sumber daya alam yang ada di sekitanya. Pada zaman batu, manusia menggunakan batu sebagai sumber pembuatan peralatan. Kemudian di zaman yang semakin canggih, manusia menggunakan berbagai logam untuk dijadikan alat yang dapat mempermudah kehidupannya. $^{2}$

Logam merupakan kelompok toksik yang unik.Logam ditemukan dan menetap di alam, tetapi bentuk kimianya dapat berubah oleh pengaruh fisikokimia, biologis atau akibat aktivitas manusia. Toksisitasnya dapat berubah drastis bila bentuk kimianya berubah. Umumnya logam bermanfaat bagi manusia karena penggunaannya dalam bidang industri, pertanian atau kedokteran. ${ }^{3}$

Beberapa logam memang banyak digunakan dalam berbagai keperluan, oleh karena itu logam banyak diproduksi secara rutin dalam skala industri. Pemanfaatan logam tersebut dalam kehidupan seharihari, telah secara langsung atau pun tidak langsung menyebabkan pencemaran pada lingkungan. Pada beberapa kasus, beberapa logam sudah pada taraf mencemari lingkungan. Beberapa jenis logam yang telah mencemari lingkungan seperti, Timbal $(\mathrm{Pb})$, Merkuri (Hg), Arsenik (As), Cadmium (Cd), Chromium (Cr) dan Nikel (Ni). Logam-logam ini telah diketahui dapat tersimpan dalam tubuh organisme dan berada di dalamnya dalam jangka waktu yang lama sebagai racun yang terakumulasi. ${ }^{4}$

Di antara kasus-kasus pencemaran akibat logam, efek toksik dari timah hitam atau timbal $(\mathrm{Pb})$ adalah yang pertama kali muncul. Banyak orang diberbagai Negara sudah mengetahui keracunan yang dapat ditimbulkan oleh timbal ini. ${ }^{5}$ Masalah pencemaran logam berat merupakan masalah yang serius di negara-negara maju dan sedang berkembang seperti Indonesia. Logam berat yang ada di lingkungan hidup 
biasanya berkaitan erat dengan proses pengecoran logam. Salah satu pusat pertumbuhan industri logam di Jawa Tengah adalah di Kabupaten Klaten yaitu tepatnya Desa Tagalrejo, Desa Ngawonggo, dan desa Batur yang berlokasi di Kecamatan Ceper. Ceper sudah ada sejak jaman kerajaan Mataram. Pada jaman penjajahan Belanda, pelaku usaha cor logam sudah mengerjakan pengecoran untuk perlengkapan pabrik gula. Pada jaman penjajahan Jepang, para pelaku cor logam sudah membuat granat dan peralatan lainnya untuk perang. Pada tahun 1973, klaten mulai semakin tumbuh sejak adanya campur tangan Pemerintah Pusat melalui Departemen perindustrian. Bantuan paling besar yang diberikan adalah dalam bentuk bantuan peralatan dan modal yang diserahkan kepada Koperasi Batur Jaya sebagai koperasi produksi. Keberadaan koperasi akan mendorong pelaku usaha untuk bekerjasama meningkatkan produksinya.

Pada tahun 1990-an Ceper pernah terkenal sebagai daerah pengecoran logam di Indonesia karena saat itu jumlah industrinya mencapai lebih dari 325 industri, bahkan kapasitas terpasang mencapai 150.000 ton atau sekitar $40 \%$ kapasitas nasional. Teknologi pengecoran yang selama ini diandalkan adalah tungkik dan kupola yaitu alat peleburan tradisional berbahan bakar kokas.

Hasil kegiatan dari industri pengecoran logam, tentunya akan berdampak negatif ke lingkungan dan berpengaruh pada kesehatan manusia. Senyawa Timah Hitam (PB) setelah meninggalkan ruang bakar akan membentuk padatan partikel, sebagian besar berdiameter kurang dari $2 \mu$, baku mutu udara ambient yang diatur oleh peraturan yang diatas mensyaratkan pengukuran partikel berukuran $10 \mu \mathrm{g}$ dan $2,5 \mu \mathrm{m}$, sedangkan baku mutu kadar timah hitam udara: $2 \mu \mathrm{g} / \mathrm{m}^{3}$ untuk pengukuran 24 jam. $^{6}$ Beberapa hasil penelitian membuktikan bahwa salah satu factor resiko adanya kadar timah hitam (PB) yang melebihi ambang batas adalah tekanan darah tinggi (hipertensi). ${ }^{7}$

Timbal yang masuk dalam aliran darah dapat menyebabkan hipertensi. timbal dapat menyebabkan meningkatnya produksi reactive oxygen species (ROS). ROS merupakan bentuk turunan dari Oksigen yang terjadi saat bereaksi dengan elektron. Sumber utama ROS adalah dari hasil respirasi selular dan proses metabolisme. Selain itu, ROS juga dapat berasal dari radiasi. ROS mempunyai peran yang krusial pada fisiologis manusia dan proses patofisiologis. ROS berperan dalam fungsi immun, tiroid, kognitif dan modulasi sensor nutrien dan umur. Dalam kaitannya dengan kesehatan ROS, berhubungan dengan implikasi beberapa penyakit seperti cancer, penyakit kardiovaskuler (termasuk hipertensi), penyakit syaraf, gangguan perasaan dan penyakit psikiatrik.

Hasil uji pendahuluan kandungan Timah Hitam $\mathrm{Pb}$ ) dalam darah pada pekerja pengecoran logam di Ceper berjumlah 33 orang, dengan baku mutu WHO $\geq 10 \mu \mathrm{g} / \mathrm{dL}$, ditemukan sebanyak $16(5,61 \%)$ pekerja kandungan $\mathrm{Pb}$ dalam darah di bawah baku mutu dan $17(5,28 \%)$ pekerja diatas baku mutu. Rata - rata pb dalam darah pada pekerja di pengecoran adalah antara $3 \mu \mathrm{g} / \mathrm{dL}$ sampai dengan $37,4 \mu \mathrm{g} / \mathrm{dL}$ dengan baku mutu menurut WHO $10 \mu \mathrm{g} / \mathrm{dL}$.

\section{MATERI DAN METODE}

Jenis penelitian ini merupakan penelitian oservasional analitik kuantitatif dengan menggunakan pendekatan cross-secsional. Variabel penelitian terdiri dari variabel bebas yaitu jenis pekerjaan dan kadar $\mathrm{Pb}$ dalam udara, variabel antara adalah kadar $\mathrm{Pb}$ dalam darah sedangkan variabel terikat yaitu kejadian hipertensi dan variabel pengganggu yaitu kelengkapan APD, umur, lama paparan perhari, masa kerja, kebiasaan olah raga kebiasaan merokok, kebiasaan konsumsi alcohol, riwayat keluarga hipertensi, IMT, peningkatan suhu tubuh dan kebisingan ruangan. Responden yang akan digunakan berjumlah 31 orang, yang keseluruhannya merupakan pekerja pengecoran logam di Cv. Bonjor Jaya Ceper Klaten. Penelitian ini menggunakan laboratorium dimana responden akan diambil sampel darah untuk pemeriksaan kadar $\mathrm{Pb}$ dalam darah dan pengambilan sampel mudara untuk mengetahui kadar $\mathrm{Pb}$ dalam udara di lingkungan kerja. Sementara uji hipotesis yang digunakan adalah $\mathrm{Chi}$ Square.

Teknik pengambilan sampel yang digunakan dalam penelitian ini adalah total sampling. Hal ini didasarkan pertimbangan bahwa subyek penelitian dapat memberikan informasi yang cukup untuk menjawab setiap pertanyaan yang diajukan peneliti dan dengan demikian diharapkan dapat digunakan oleh peneliti selanjutnya untuk dapat diamati perkembangan penelitian di tahun berikutnya.

\section{HASIL DAN PEMBAHASAN}

\section{Analisi Univariat}

Hasil analisis karakteristik responden dapat dilihat rata-rata umur responden pada penelitian ini adalah 35.48 tahun dengan nilai standar deviasi 9.081 serata nilai minimal 17 dan nilai maksimal 54.

Tabel 1. Karakteristik responden dan hasil Pemeriksaan

\begin{tabular}{llcc}
\hline No & Variabel & f & $\%$ \\
\hline 1 & Umur & 5 & 16,1 \\
& 15-24 tahun & 9 & 29,0 \\
& 25-34tahun & 13 & 41,9 \\
& 35-44tahun & 4 & 12,9 \\
& 45-54tahun & & \\
2 & Jenis pekerjaan & 8 & 25,8 \\
& Pengecor & 10 & 32,3 \\
& Pencetak & 13 & 41,9 \\
& Finishing & & \\
3 & Masa Kerja & 25 & 80,6 \\
& $>5$ tahun & 6 & 19,4
\end{tabular}




\begin{tabular}{|c|c|c|c|}
\hline 4 & $\begin{array}{l}\text { Lama kerja perhari } \\
>8 \text { jam } \\
\leq 8 \mathrm{jam}\end{array}$ & $\begin{array}{l}10 \\
21\end{array}$ & $\begin{array}{l}32,3 \\
67,7\end{array}$ \\
\hline \multirow[t]{3}{*}{5} & Pemakaian APd & & \\
\hline & Tidak lengkap & 14 & 45,2 \\
\hline & Lengkap & 17 & 54,8 \\
\hline \multirow[t]{2}{*}{6} & $\mathrm{~Pb}$ dalam udara & & \\
\hline & $\begin{array}{l}>10 \mu \mathrm{g} / \mathrm{dl} \\
<10 \mu \mathrm{g} / \mathrm{dl}\end{array}$ & $\begin{array}{l}18 \\
13\end{array}$ & $\begin{array}{l}58,1 \\
41,9\end{array}$ \\
\hline \multirow[t]{3}{*}{7} & $\mathrm{~Pb}$ dalam darah & & \\
\hline & Di atas normal & 16 & 51,6 \\
\hline & Normal & 15 & 48,4 \\
\hline \multirow[t]{3}{*}{8} & Kejadian Hipertensi & & \\
\hline & Hipertensi & 26 & 83,9 \\
\hline & Tidak Hipertensi & 5 & 16,1 \\
\hline
\end{tabular}

Rata-rata lama kerja perhari pekerja CV. Bonjor Jaya sebesar 85,16 perhari dengan nilai minimal 7 jam dan nilai maksimal 11 jam serta memiliki nilai standar deviasi 0,9 . Pekerja yang paling lama bekerja di CV. Bonjor Jaya adalah selama 28 tahun dengan rata-rata 1 tahun dan standar deviasi 7,6. Hasil pemeriksaan nilai kadar $\mathrm{Pb}$ dalam udara tertinggi $0.212 \mu \mathrm{g} / \mathrm{dl}$, dengan rata-rata $0.13756 \mu \mathrm{g} / \mathrm{dl}$ dan standar deviasi 0.086904 . Jumlah responden yang memiliki nilai kadar $\mathrm{Pb}$ dalam darah paling tinggi sebesar $37.40 \mu \mathrm{g} / \mathrm{dl}$ dengan rata-rata $14.38096 \mu \mathrm{g} / \mathrm{dl}$ dan standar deviasi 10.11195 .

Jenis pekerjaan pada CV. Bonjor Jaya dikategorikan menjadi 3 bagian, sesuai dengan bagian-bagian kerja yang terdapat di CV. Bonjor Jaya. Mengacu pada table 1 tentang distribusi karakteristik responden pembagiannya adalah pekerja dibagian pengecor sebanyak 8 orang $(25,8 \%)$, pencetak sebanyak 10 orang $(32,3 \%)$ dan dibagian finishing sebanyak 13 orang (41,9\%). Responden yang memiliki masa kerja $>5$ tahun di CV. Bonjor Jaya sebanyak 19 orang $(61,3 \%)$. Responden dengan lama kerja perhari yang melebihi ketentuan dari Kepmenakertrans yaitu 8 jam/hari ada sebanyak 10 orang $(32,3 \%)$. Kadar $\mathrm{Pb}$ dalam ruangan kerja dikatakan normal jika $<0,05 \mathrm{mg} / \mathrm{Nm}^{3}$, kadar $\mathrm{Pb}$ dalam ruangan kerja $\mathrm{CV}$, Bonjor Jaya $58,1 \%$ diatas normal. Kadar $\mathrm{Pb}$ dalam darah dikatakan tidak normal jika $\geq$ $10 \mu \mathrm{g} / \mathrm{dl}$ berdsasarkan peraturan yang dikeluarkan oleh NIOSH dan WHO, dari 31 orang sebanyak 16 orang
$(51,6 \%)$ memiliki $\mathrm{Pb}$ dalam darah diatas normal dan 15 orang $(48,4 \%) \mathrm{Pb}$ dalam darahnya normal. Pemeriksaan tekanan darah dengan mengguanakan tensi meter, berdasarkan diagnose dokter, dimana 26 orang $(83,9 \%)$ dinyatakan hipertensi dan 5 orang $(16,1 \%)$ dinyatakan normal atau tidak menderita hipertensi.

\section{Analisis bivariat \\ Hubungan Jenis Pekerjaan dengan Kejadian Hipertensi}

Pengelompokan jenis pekerjaan disini dibagi dalam 2 jenis yaitu jenis pekerjaan yang berisiko dan tidak berisiko. Jenis pekerjaan yang berisiko adalah nilai kadar $\mathrm{Pb}$ udara diatas $\mathrm{NAB}$ yaitu diatas 0,05 $\mathrm{mg} / \mathrm{Nm}^{3}$ sedangkan pekerjaan yang tidak berisiko adalah nilai kadar $\mathrm{Pb}$ udara di bawah NAB. Tempat pekerjaan diatas nilai $\mathrm{NAB}$ adalah di ruang kerja pengecoran dengan nilai $\mathrm{Pb}$ udara $0,208 \mathrm{mg} / \mathrm{Nm}^{3}$ dan ruang kerja bagian pencetakan dengan nilai $\mathrm{Pb}$ udara $0,212 \mathrm{mg} / \mathrm{Nm}^{3}$. Ruang kerja yang tidak berisiko adalah ruang kerja bagian finising dengan nilai kadar $\mathrm{Pb}$ udara $0,037 \mathrm{mg} / \mathrm{Nm}^{3}$. Untuk mengetahui hubungan antara jenis pekerjaan yang dilihat dari faktor beresiko dan tidak berisiko terhadap paparan $\mathrm{Pb}$ dengan kejadian hipertensi dilakukan tabulasi silang dan uji statistik dengan hasil pada tabel 2.

Pada tabel 2 diperoleh nilai significancy ( $p$ ) 0,625 yang menunnjukkan bahwa tidak ada hubungan antara jenis pekerjaan dengan hipertensi. Prosentase pekerja pada bagian yang berisiko menderita hipertensi adalah $88,9 \%$ sebanyak 16 pekerja dari 18 pekerja pada bagian yang berisiko menderita Hipertensi, sedangkan prosentase pekerja yang menderita hipertensi pada bagian yang tidak berisiko adalah $76,9 \%$ sebanyak 10 orang dari 13 orang pada bagian yang tidak berisiko menderita hipertensi. Secara keseluruhan pekerja pengecoran logam CV Bonjor Jaya yang menderita hipertensi adalah 83,9 \% atau 26 pekerja yang mengalami hipertensi dari 31 pekerja.

Tabel 2 : Hubungan antara jenis pekerjaan dengan hipertensi pada pekerja pengecoran loga CV, Bonjor Jaya.

\begin{tabular}{lcccccc}
\hline Jenis Pekerjaan & \multicolumn{3}{c}{ Kejadian Hipertensi } & & Total & $\%$ \\
& Hipertensi & $\%$ & Tidak Hipertensi & $\%$ & & \\
\hline Beresiko & 16 & 88,9 & 2 & 11,1 & 18 & $100 \%$ \\
Tidak berisiko & 10 & 76,9 & 3 & 23,1 & 13 & $100 \%$ \\
Jumlah & 26 & 83.9 & 5 & 16.1 & 31 & $100 \%$ \\
\hline$P=0,625 \quad \mathrm{PR}=1,156 \quad \mathrm{CI}=0,823-1,623$ & \multicolumn{7}{l}{} & & & & \\
\hline
\end{tabular}


Hubungan kadar Pb udara dengan Pb dalam darah

Untuk mengetahui hubungan antara kadar $\mathrm{Pb}$ Udara dengan nilai NAB $0,05 \mathrm{mg} / \mathrm{Nm}^{3}$ dengan $\mathrm{Pb}$ dalam darah dengan nilai NAB $10 \mu \mathrm{g} / \mathrm{dl}$ dilakukan tabulasi silang dan uji statistik dengan hasil seperti pada table 3 .

Tabel 3: Hubungan antara $\mathrm{Pb}$ udara dengan $\mathrm{Pb}$ dalam darah pada pekerja pengecoran logan $\mathrm{CV}$, Bonjor Jaya.

\begin{tabular}{|c|c|c|c|c|c|}
\hline \multirow[t]{3}{*}{$\mathrm{Pb}$ Udara } & \multicolumn{4}{|c|}{ Kadar Pb Dalam Darah } & \multirow{3}{*}{ Total } \\
\hline & \multicolumn{2}{|c|}{ Tidak Normal } & \multicolumn{2}{|c|}{ Normal } & \\
\hline & $\mathrm{f}$ & $\%$ & $\mathrm{f}$ & $\%$ & \\
\hline$>\mathrm{NAB}$ & 13 & 72.2 & 5 & 27.8 & 18 \\
\hline$\leq \mathrm{NAB}$ & 3 & 23.1 & 10 & 76.9 & 13 \\
\hline Total & 16 & 51.6 & 15 & 48.4 & 31 \\
\hline
\end{tabular}

Proporsi responden yang bekerja dibagian yang melebihi $\mathrm{NAB}$ dan kadar $\mathrm{Pb}$ darah diatas normal 72.2 $\%$ sebanyak 13 orang. Proporsi responden yang bekerja di bagian di bawah NAB dan kadar Pb darah diatas normal $23.1 \%$ sebanyak 3 orang. Hasil uji statistik membuktikan ada hubungan yang signifikan antara $\mathrm{Pb}$ di udara dengn $\mathrm{Pb}$ dalam darah dengan $\mathrm{p}$ valua $0,019 \quad(<0.05)$ dengan nilai $P R$ adalah ukuran asosiasi paparan ( faktor resiko) dengan kejadian penyakit. Berdasarkan hasil di atas maka pekerja yang berada pada $\mathrm{Pb}$ udara diatas normal 3 kali lebih besar dari pada pekerja dengan $\mathrm{Pb}$ udara normal yaitu sebesar 3,130. Kesimpulan paparan debu $\mathrm{Pb}$ di udara merupakan faktor resiko terjadinya gangguan PB darah diatas normal pada pekerja pengecoran logam di CV Bonjor Jaya dan CI sebesar 1.114-8,793.

Hubungan antara kadar Pb dalam darah dengan kejadian hipertensi

Penelitian ini ingin melihat hubungan antara $\mathrm{Pb}$ dalam darah dengan nilai NAB $10 \mu \mathrm{g} / \mathrm{dl}$ yang salah satunya didapatkan dari udara yang menyebabkan kadar $\mathrm{Pb}$ dalam darah menjadi meningkat, kadar $\mathrm{Pb}$ di dalam darah diatas normal adalah satu yang menyebabkan terjadinya peningkatan tekanan darah atau hipertensi dengan batasan diagnosa Hipertensi $>$ 90-140 $\mathrm{mm} \mathrm{Hg}$, adapun hasil dari penelitian ini adalah;

Tabel 4: Hubungan antara kadar $\mathrm{Pb}$ dalam darah dengan kejadian Hipertensi pada pekerja pengecoran logam CV. Bonjor Jaya

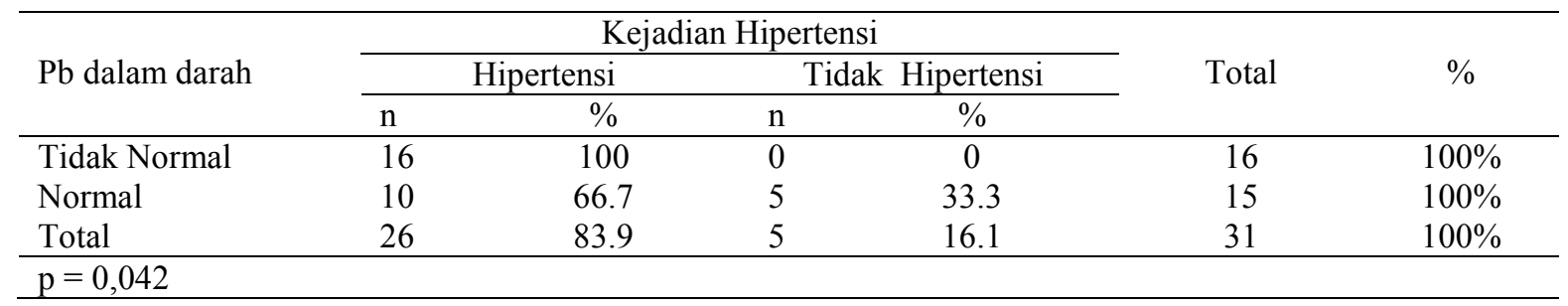

Proporsi responden yang $\mathrm{Pb}$ dalam darah diatas normal dan Hipertensi $100 \%$ sebanyak 16 orang, sedangkan Proporsi responden $\mathrm{Pb}$ dalam darah normal dan kejadian hipertensi $66.7 \%$ sebanyak 10 orang. Dari hasil uji statistik membuktikan ada hubungan yang signifikan antara $\mathrm{Pb}$ dalam darah dengan kejadian hipertensi $p=0,042$ dibandingkan dengan alpha 0.05 maka dapat disimpulkan kadar $\mathrm{Pb}$ dalam darah merupakan faktor resiko terjadinya kejadian Hipertensi pada pekerja pengecoran logam di CV Bonjor Jaya.

\section{SIMPULAN}

Berdasarkan hasil penelitian, analisis, dan pembahasan riwayat papara Timbal $(\mathrm{Pb})$ dalam darah dengan hipertensi pada pekerja pengecoran logam CV. Bonjor Jaya, Desa Batur, Kecamatan Ceper, Klaten dapat disimpulkan sebagai berikut :

1. Sebanyak 51\% ( 16 orang dari 31 pekerja) memiliki kadar $\mathrm{Pb}$ (timbal) dalam darah melebihi baku mutu yang telah ditetapkan oleh NIOSH (National Institute for Occupational Safety and Health) sekitar $10 \mu \mathrm{g} / \mathrm{dl}$ untuk dewasa.

2. Pekereja yang mengalami hipertensi berdasarkan hasil pemeriksaan dengan menggunakan tensi meter adalah $(83,9 \%)$ sebanyak 26 orang dari 31 pekerja. 
3. Tidak ada hubungan antara jenis pekerjaan dengan kejadian hipertensi pada pekerja pengecoran logam $(p=0,625) \mathrm{CV}$. Bonjor Jaya, Desa Batur, Ceper, Klaten.

4. Ada hubungan antara kadar $\mathrm{Pb}$ dalam udara dengan kadar $\mathrm{Pb}$ dalam darah pada pekerja pengecoran logam d Cv. Bonjor Jaya Desa Batur, Kecamatan Ceper, Klaten $(p=0,019)$

5. Ada hubungan antara kadar $\mathrm{Pb}$ dalam darah dengan kejadian hipertensi pada pekerja pengecoran logam Cv. Bonjor Jaya Desa Batur, Kecamatan Ceper, Klaten ( $\mathrm{p}=0,042)$.

\section{DAFTAR PUSTAKA}

1. Irena Sherameti, Soil Heavy Metals, Soil Biology: Soil Heavy Metals vol.19.2010

2. Soemirat, J. Toksikologi Lingkungan. Yogyakarta: Gadjah Mada University Press .(2005)

3. Frank, C. Lu. (2006). Toksikologi Dasar. Jakarta: Universitas Indonesia Press

4. Fardiaz, S..Pencemaran Air dan Udara. Yogyakarta: Kanisius (1992)

5. Mehrpour, O., Karrari, P., Abdollahi, M. Chronic Lead Poisoning in Iran; a Silent DeseaseEditorial.DARU Journal of Pharmaceutical Sciences, Vol. 20, No. 8 (2012).

6. Wahyu Widowati, Astiana Sastiono, Raymond jusuf. Efek mToksik Logam Pencegahan dan penanganana Pencemaran. Penerbit C.V Andi Offset Yogyakarta: 2008.

7. Boedhi -Darmojo. Mengamati Perjalanan Epidemiologi hipertensi di Indonesia. Medikia, 2001; 7: 442-448 